\title{
Dynamic Shear Characteristic and Fracture Feature of Inconel 690 Alloy under Different High Strain Rates and Temperatures
}

\author{
Tao-Hsing Chen, Chih-Kai Tsai, and Te-Hua Fang \\ Department of Mechanical Engineering, National Kaohsiung University of Applied Sciences, Kaohsiung 807, Taiwan \\ Correspondence should be addressed to Tao-Hsing Chen; thchen@cc.kuas.edu.tw
}

Received 13 September 2013; Accepted 6 October 2013

Academic Editor: Jacques Huot

Copyright (C) 2013 Tao-Hsing Chen et al. This is an open access article distributed under the Creative Commons Attribution License, which permits unrestricted use, distribution, and reproduction in any medium, provided the original work is properly cited.

The high strain shear rate behaviour of Inconel 690 alloy was investigated by using the split Hopkinson torsional bar. The shear strain rates were tested at $900 \mathrm{~s}^{-1}, 1900 \mathrm{~s}^{-1}$, and $2600 \mathrm{~s}^{-1}$ and at temperatures of $-100^{\circ} \mathrm{C}, 25^{\circ} \mathrm{C}$, and $300^{\circ} \mathrm{C}$, respectively. It was found that the dynamic shear behaviour of Inconel 690 alloy was sensitive to strain rate and temperature. The fracture shear strain increased with increasing strain rate and temperature. In addition, the strain rate sensitivity was increased with increasing strain and strain rate but decreased with increasing temperature. Finally, the fracture surfaces were found to contain dimple-like features, and the dimple density increased with increasing strain rate and temperature.

\section{Introduction}

The Inconel 690 alloy is well used in gas turbines, nuclear reactors, spacecraft, and liquid rocket engine. The literature contains many investigations into the static properties of Inconel 690 [1-6]. Moreover, the interactive effects of strain rate and temperature on the fundamental mechanical properties of metals and alloys under high strain rate loading are much stronger than those under static loading. Thus, while the static properties of Inconel 690 alloy are well understood [7-10], the dynamic properties of Inconel 690 under shear loading over a wide range of temperatures require further investigation. However, during the structural component fabrication or subsequent service lives, Inconel 690 alloys are commonly subjected to high strain rate loading. Furthermore, such components are deployed under a wide range of temperature conditions. In order to investigate the ability of Inconel 690 alloy components to withstand the temperature and strain rate condition they are likely to experience in an actual fabrication and service environment, it is necessary to obtain detailed insights into the strain rate properties and failure characteristics of Inconel 690 alloy under different temperature conditions [11].

In this study, the dynamic shear deformation behaviour of Inconel 690 alloy is investigated using a torsional SHPB system at shear strain rates of $900 \mathrm{~s}^{-1}, 1900 \mathrm{~s}^{-1}$, and $2600 \mathrm{~s}^{-1}$ and temperatures of $-100^{\circ} \mathrm{C}, 25^{\circ} \mathrm{C}$, and $300^{\circ} \mathrm{C}$, respectively. The fracture surfaces are examined via scanning electron microscopy (SEM). The correlation between the dynamic shear response of the Inconel 690 specimens and the fracture features is systematically analysed and discussed.

\section{Experimental Procedure}

Inconel 690 alloy with a composition of $29.3 \% \mathrm{Cr}, 10.05 \% \mathrm{Fe}$, $0.3 \% \mathrm{Ti}, 0.2 \% \mathrm{Al}, 0.15 \% \mathrm{Cu}, 0.03 \% \mathrm{Co}, 0.03 \% \mathrm{Mo}, 0.03 \% \mathrm{~W}$, and $0.01 \% \mathrm{C}$ and a balance of $\mathrm{Ni}$ (mass) was purchased from Gloria Material Technology Corp., Taiwan. Twin-flanged thin-walled tubular specimens with an outer diameter (OD) of $12 \mathrm{~mm}$ and a length of $11.5 \mathrm{~mm}$ were then machined from the bars. Figure 1 presents a schematic illustration of the final tubular specimen with an inner diameter of $5 \mathrm{~mm}$ and a wall thickness of $0.3 \mathrm{~mm}$ in the central gauge section.

Dynamic shear tests were performed at strain rates of $900 \mathrm{~s}^{-1}, 1900 \mathrm{~s}^{-1}$, and $2600 \mathrm{~s}^{-1}$, at temperatures of $-100^{\circ} \mathrm{C}$, $25^{\circ} \mathrm{C}$, and $300^{\circ} \mathrm{C}$, respectively, by using a split Hopkinson torsional bar system. In performing the tests, the specimen was mounted between the incident bar and the transmitted bar of the torsional SHPB system. Moreover, the test 


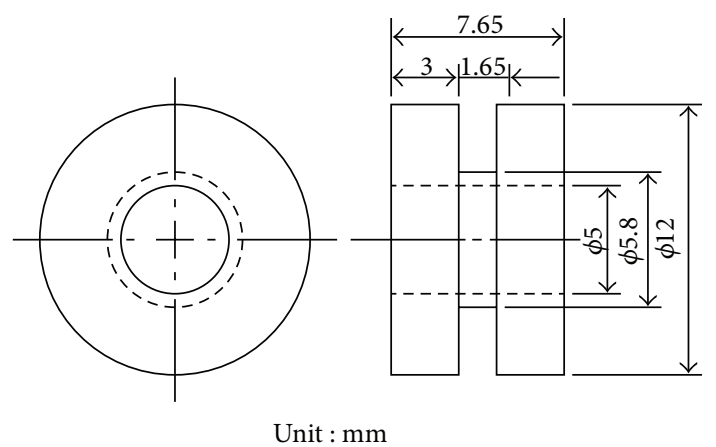

FIGURE 1: Schematic of shearing test specimens.

temperature of $-100^{\circ} \mathrm{C}$ was tested by using a refrigeration system positioned around the specimen and filled with liquid nitrogen and alcohol. The test temperature of $300^{\circ} \mathrm{C}$ was monitored using a K-type thermocouple with an accuracy of $\pm 2^{\circ} \mathrm{C}$ attached directly to the specimen. The two bars had a diameter of $12.7 \mathrm{~mm}$ and a length of $1000 \mathrm{~mm}$ and were both machined from 7075-T6 aluminum alloy.

The spit-Hopkinson torsional bar system experimental apparatus contained the incident bar and the transmitted bar, and the specimen was positioned between the two bars. During testing, the incident bar was held in place by a clamp while a torque was applied to its free end. Then, the clamp was quickly released causing an incident torsional strain pulse. At the interface between the incident bar and the specimen, it generated transmitted pulse and reflected pulse. The amplitudes of the incident, reflected, and transmitted pulses were measured using strain gauges mounted on the incident and transmitted bars, respectively $[12,13]$. Note that the full details of the experimental procedure and analytical technique used to evaluate the dynamic mechanical response of the shear specimens are presented in the author's present study $[12,13]$ and are therefore omitted here. After dynamic shear testing, the deformed specimens were sectioned parallel to the longitudinal axis. The sections were ground and polished using conventional techniques and were then etched in an acidic solution of $3 \mathrm{~mL} \mathrm{HNO}_{3}, 2 \mathrm{~mL} \mathrm{HF}$, and $95 \mathrm{~mL}$ $\mathrm{H}_{2} \mathrm{O}$ for approximately $5 \mathrm{~s}$. Finally, the fracture surfaces were observed using an optical microscope. The detailed characteristics of the fracture surfaces were identified using a Hitachi filed emission scanning electron microscope (SEM) with an accelerating voltage of $15 \mathrm{kV}$, work distance of $32 \mathrm{~mm}$, and SE signal.

\section{Results and Discussion}

3.1. Shear Stress-Strain Response. Figure 2 shows the shear stress-strain curves of the Inconel 690 specimens deformed at different strain rates and temperatures. It is seen that the flow stress increases with increasing strain rate but decreases with increasing temperature. Furthermore, the fracture strain varies as a function of both the strain rate. Table 1 shows the effects of the strain rate and temperature on the fracture strain of the Inconel 690 specimens. It can be observed that,

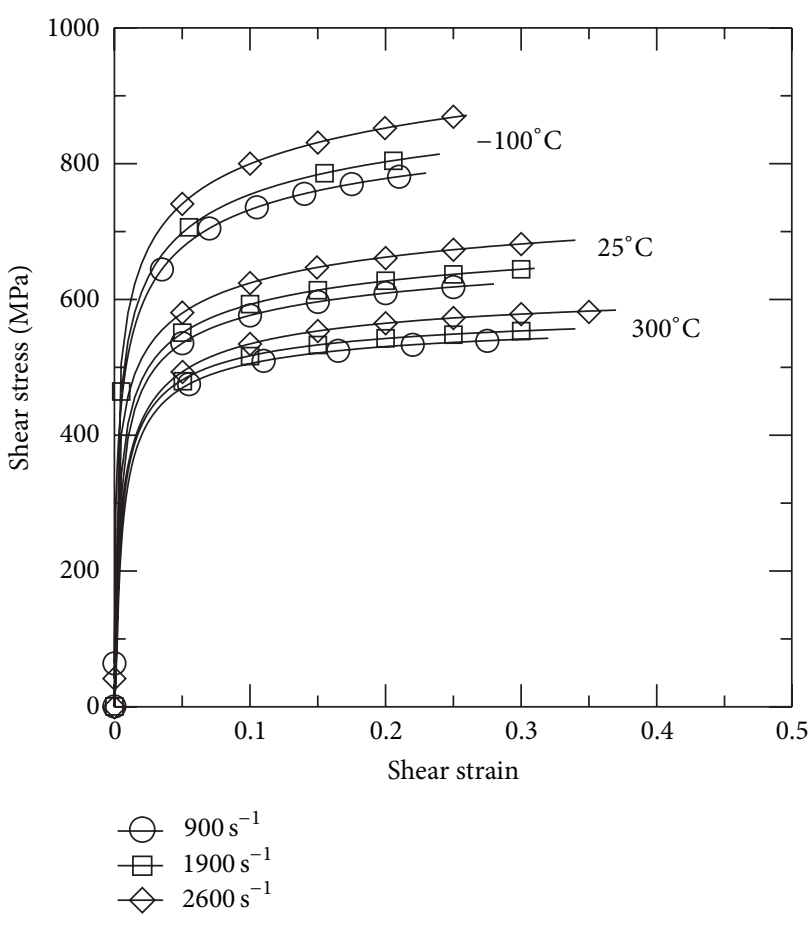

Figure 2: The shear stress-strain curves of Inconel 690 alloy deformed at different strain rates and temperatures.

TABLE 1: Variation of fracture shear stress with fracture shear strain as a function of strain rate and temperature.

\begin{tabular}{lcc}
\hline Temperature & Shear strain rate $\left(\mathrm{s}^{-1}\right)$ & Fracture strain $\left(\varepsilon_{f}\right)$ \\
\hline \multirow{2}{*}{$-100^{\circ} \mathrm{C}$} & 900 & 0.24 \\
& 1900 & 0.25 \\
& 2600 & 0.27 \\
\hline \multirow{2}{*}{$25^{\circ} \mathrm{C}$} & 900 & 0.29 \\
& 1900 & 0.31 \\
$300^{\circ} \mathrm{C}$ & 2600 & 0.35 \\
& 900 & 0.32 \\
& 1900 & 0.36 \\
\hline
\end{tabular}

for a constant temperature, the fracture shear strain increases with increasing strain rate. Meanwhile, for a constant strain rate, the fracture shear strain increases with increasing temperature. In other words, the ductility of Inconel 690 increases under high strain rate loading and high temperature tested conditions. It is thought that the ductility enhancement is the result of a deformation-induced temperature rise prompted by the interaction between the high strain rate and the high temperature.

3.2. Effects of Strain Rate. To realize the effect of the strain rate on the shear response of Inconel 690 alloy, Figure 3(a) plots the variation of the shear stress with the strain rate as a function of the temperature and shear strain. It is seen 


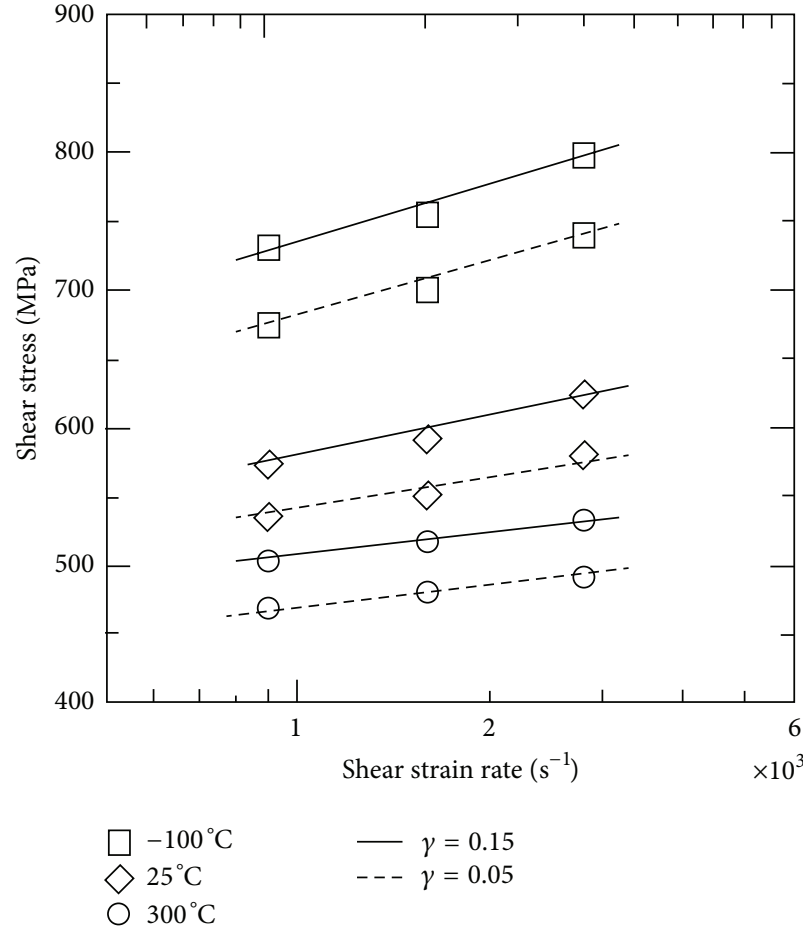

(a)

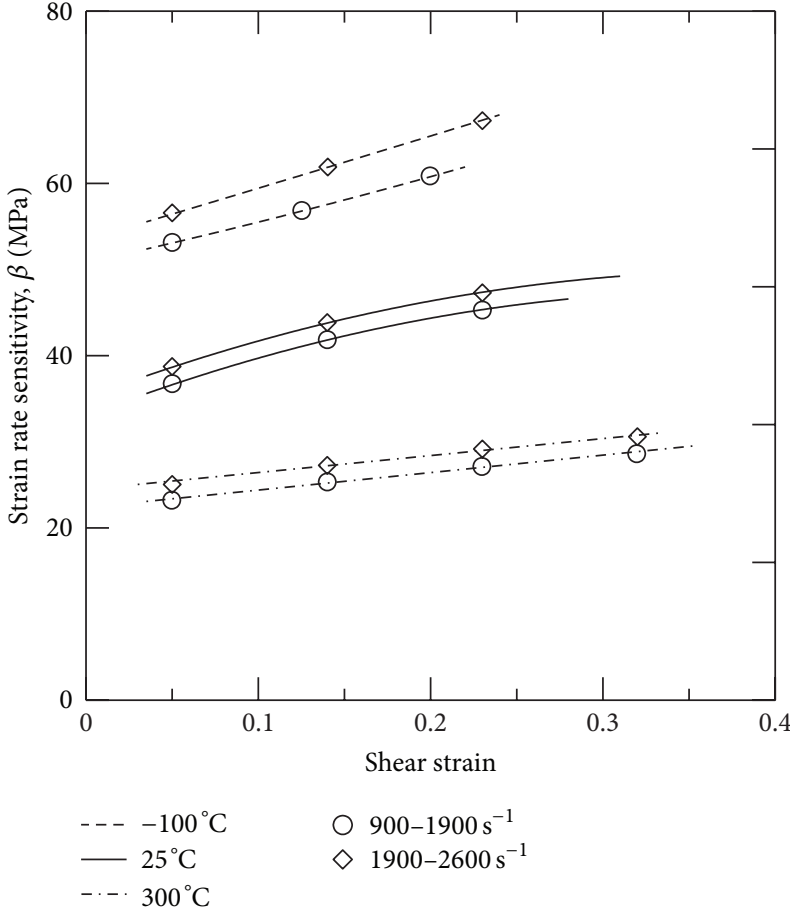

(b)

FIGURE 3: (a) Variation of shear stress with logarithmic strain rate as a function of temperature for constant shear strains of 0.05 and 0.15 . (b) Variation of strain rate sensitivity with shear strain as a function of temperature and strain rate.

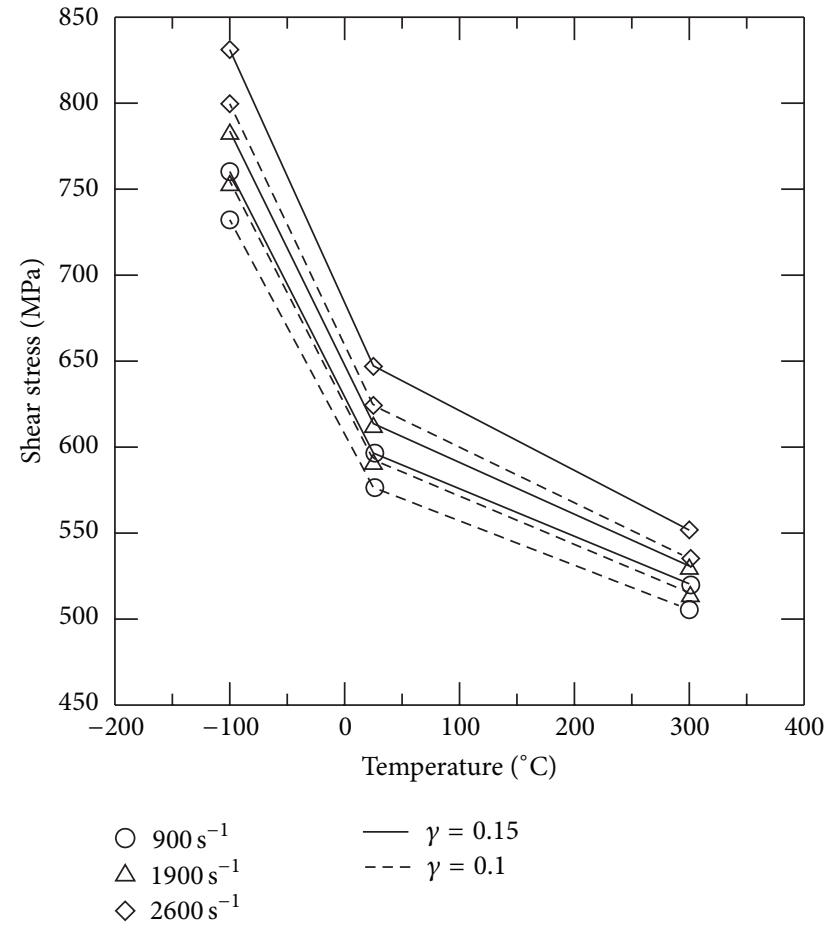

FIGURE 4: Variation of shear stress with temperature as a function of strain rate and strain.

that the flow stress increases with increasing strain rate. The effect of the strain rate on the shear stress can be quantified

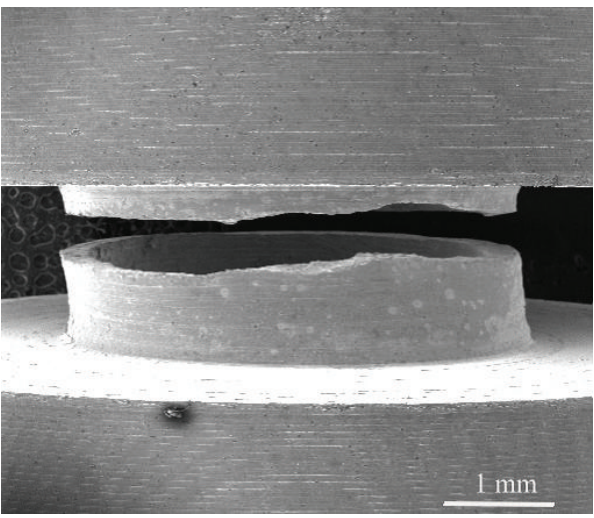

FIGURE 5: Micrographs (SEM) of specimens fractured at strain rate of $2600 \mathrm{~s}^{-1}$ and temperature of $25^{\circ} \mathrm{C}$.

via the strain rate sensitivity parameter $\beta$ (equivalent to the gradient of the $\tau$ versus $\log \gamma$ plot [14]); that is,

$$
\beta=\frac{\left(\tau_{2}-\tau_{1}\right)}{\ln \left(\dot{\gamma}_{2} / \dot{\gamma}_{1}\right)},
$$

where the shear stresses $\tau_{1}$ and $\tau_{2}$ are obtained from shear tests conducted at average strain rates of $\dot{\gamma}_{1}$ and $\dot{\gamma}_{2}$, respectively, and are calculated at the same value of the shear strain. Figure 3(b) plots the strain rate sensitivity of the Inconel 690 specimens against the shear strain as a function of the strain rate and temperature. It can be seen that, for a given temperature, the strain rate sensitivity increases 


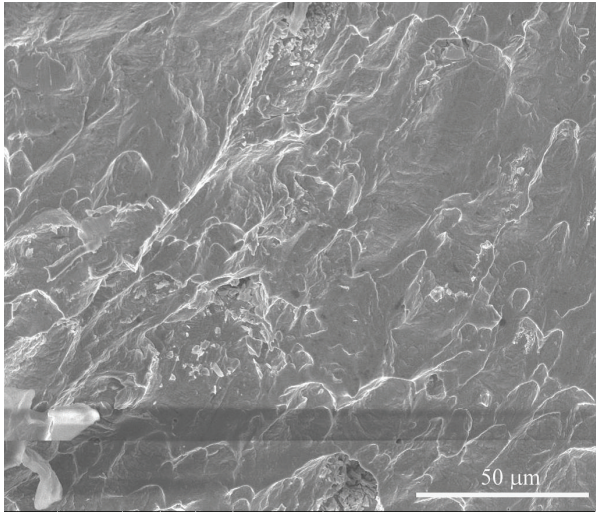

(a)

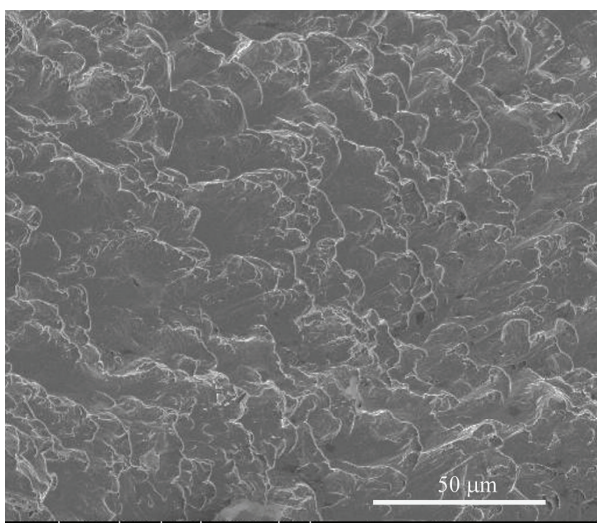

(c)

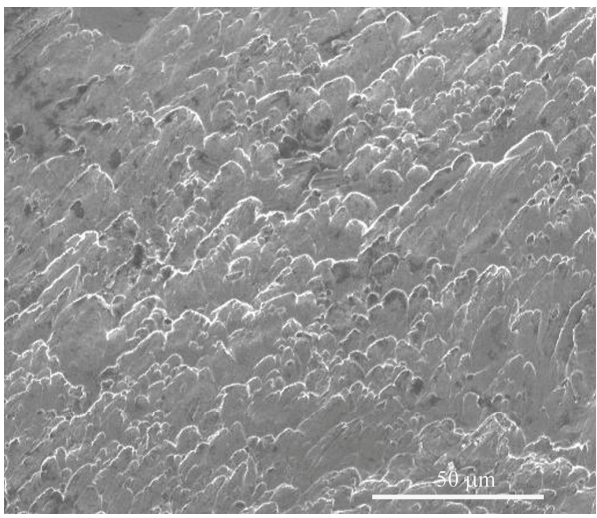

(e)

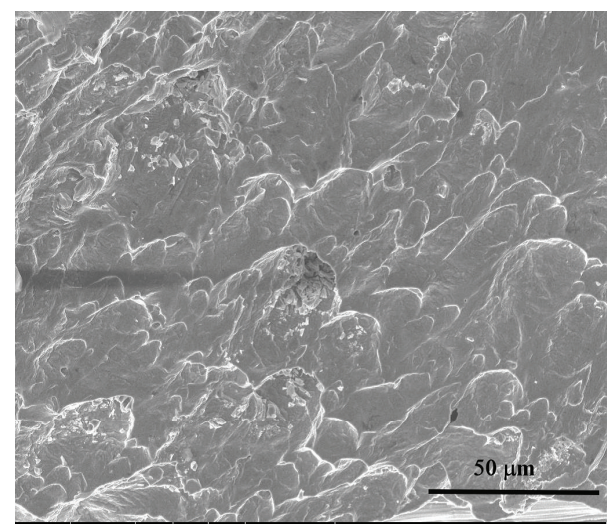

(b)

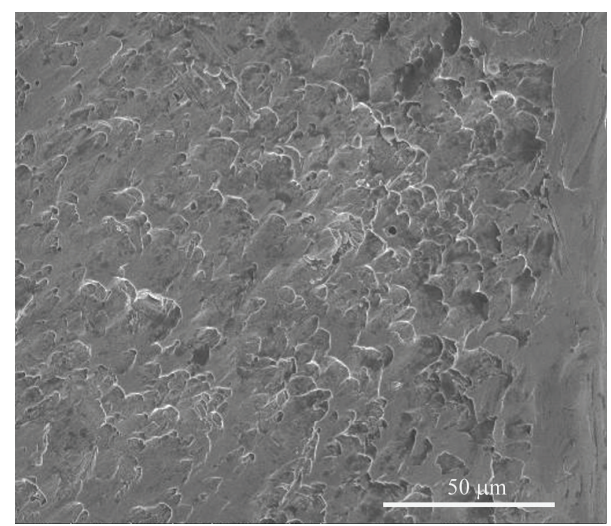

(d)

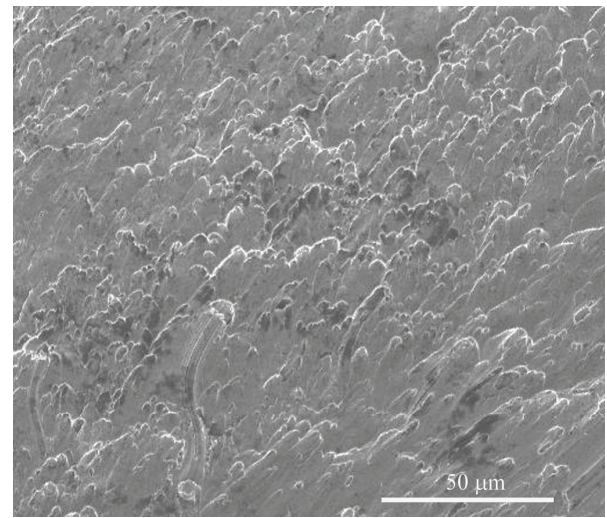

(f)

FIGURE 6: SEM figure of fracture surfaces of specimens deformed at different temperatures and strain rates: (a) $-100^{\circ} \mathrm{C}, 900 \mathrm{~s}^{-1} ;(\mathrm{b})-100^{\circ} \mathrm{C}$, $2600 \mathrm{~s}^{-1}$; (c) $25^{\circ} \mathrm{C}, 900 \mathrm{~s}^{-1}$; (d) $25^{\circ} \mathrm{C}, 2600 \mathrm{~s}^{-1}$; (e) $300^{\circ} \mathrm{C}, 900 \mathrm{~s}^{-1}$; and (f) $300^{\circ} \mathrm{C}, 2600 \mathrm{~s}^{-1}$.

with increasing strain rate. In addition, it is observed that the strain rate sensitivity increases relatively slowly with increasing shear strain at $300^{\circ} \mathrm{C}$ but increases more rapidly at $-100^{\circ} \mathrm{C}$.

3.3. Effects of Temperature. It can be observed from the shear stress-strain behaviour of Inconel 690 alloy that the flow stress is significantly dependent on the test temperature. In Figure 2, it can be seen that the higher the temperature, the lower the shear stress. Therefore, Figure 4 illustrates the temperature dependence of the flow stress for specimens deformed at different strains and strain rates. For a given shear strain and strain rate, the flow stress decreases dramatically with increasing temperature. It also can be seen that the rate of the decrease in the flow stress with increasing temperature is more pronounced at higher strain rates and larger strains. This can be attributed to the temperature rise generated in the specimen as a result of deformation heating [15]. 
3.4. Fractographic Analysis and Fracture Surface Observation. Fractographic analysis of the Inconel 690 deformed specimens reveals that the primary fracture mechanism is the intense localized shearing. Figure 5 presents low magnification SEM image of specimen deformed at strain rate of $2600 \mathrm{~s}^{-1}$ and temperature of $25^{\circ} \mathrm{C}$. Moreover, the same fracture feature in the other testing strain rates and temperatures conditions can be oberved. Variations in the strain rate and temperature affect not only the stress-strain response of the Inconel 690 alloy specimens but also the fracture behaviour of the Inconel 690 alloy. Figures 6(a) and $6(\mathrm{~b})$ present SEM images of the fracture surfaces of the specimens deformed at a temperature of $-100^{\circ} \mathrm{C}$ under strain rates of $900 \mathrm{~s}^{-1}$ and $2600 \mathrm{~s}^{-1}$, respectively. It is seen that both fracture surfaces contain dimple-like features aligned along the shear direction, which suggests a ductile fracture mode. In addition, it is seen that the density of the dimple-like features increases as the strain rate is increased. Figures 6(c) and 6(d) show the fracture surfaces of the specimens deformed at a temperature of $25^{\circ} \mathrm{C}$ and strain rates of $900 \mathrm{~s}^{-1}$ and $2600 \mathrm{~s}^{-1}$, respectively. Comparing the fracture surfaces shown in Figures 6(c) and 6(d) with those shown in Figures 6(a) and 6(b), respectively, it is seen that the density of the dimples increases with increasing temperature. In other words, the ductility of Inconel 690 alloy increases with an increasing deformation temperature. Figures 6(e) and 6(f) show the fracture surfaces of the specimens deformed at a temperature of $300^{\circ} \mathrm{C}$ under strain rates of $900 \mathrm{~s}^{-1}$ and $2600 \mathrm{~s}^{-1}$, respectively. The same fracture feature can also be oberved. Figures 6(a)-6(f) indicate that the nature of the dimple structure is significantly influenced by the strain rate and the temperature. The increase in dimple density observed with increasing strain rate and temperature leads to a greater amount of plastic deformation and hence enhances the ductile response of the material. In general, the variation in the fracture features is consistent with the tendencies of the stress-strain curves presented in Figure 2 and accounts for the higher fracture strain observed in the specimens tested at higher strain rates and temperatures.

\section{Conclusions}

This study has examined the dynamic shear deformation behaviour of Inconel 690 alloy at shear strain rates of $900 \mathrm{~s}^{-1}$, $1900 \mathrm{~s}^{-1}$, and $2600 \mathrm{~s}^{-1}$ and temperatures of $-100^{\circ} \mathrm{C}, 25^{\circ} \mathrm{C}$, and $300^{\circ} \mathrm{C}$, respectively. The results have shown that the dynamic shear response of Inconel 690 alloy is significantly dependent on the strain rate and temperature. The shear stress increases with increasing strain rate but decreases with increasing temperature. Meanwhile, the fracture strain reduces with reducing temperature but increases with increasing strain rate. The strain rate sensitivity increases with increasing strain rate and decreasing temperature. Finally, the SEM observations have shown that the Inconel 690 samples fail in a predominantly ductile mode and exhibit a greater ductility under elevated strain rates.

\section{Acknowledgment}

The authors gratefully acknowledge the financial support provided to this study by the National Science Council of Grant no. NSC101-2221-E-151-015.

\section{References}

[1] J.-K. Hong, I.-S. Kim, C.-Y. Park, and E.-S. Kim, "Microstructural effects on the fretting wear of Inconel 690 steam generator tube," Wear, vol. 259, no. 1-6, pp. 349-355, 2005.

[2] V. Venkatesh and H. J. Rack, "Elevated temperature hardening of INCONEL 690," Mechanics of Materials, vol. 30, no. 1, pp. 6981, 1998.

[3] Y. F. Yin and R. G. Faulkner, "Model predictions of grain boundary chromium depletion in Inconel 690," Corrosion Science, vol. 49, no. 5, pp. 2177-2197, 2007.

[4] D. Zhu, C.-W. Kim, and D. E. Day, "Corrosion behavior of Inconel 690 and 693 in an iron phosphate melt," Journal of Nuclear Materials, vol. 336, no. 1, pp. 47-53, 2005.

[5] V. Venkatesh and H. J. Rack, "A neural network approach to elevated temperature creep-fatigue life prediction," International Journal of Fatigue, vol. 21, no. 3, pp. 225-234, 1999.

[6] J. M. Boursier, D. Desjardins, and F. Vaillant, "The influence of the strain-rate on the stress corrosion cracking of alloy 600 in high temperature primary water," Corrosion Science, vol. 37, no. 3, pp. 493-508, 1995.

[7] J. J. Kai and M. N. Liu, "The effects of heat treatment on the carbide evolution and the chromium depletion along grain boundary of inconel 690 alloy," Scripta Metallurgica, vol. 23, no. 1, pp. 17-22, 1989.

[8] S. Guo, D. Li, H. Pen, Q. Guo, and J. Hu, "Hot deformation and processing maps of Inconel 690 superalloy," Journal of Nuclear Materials, vol. 410, no. 1-3, pp. 52-58, 2011.

[9] H.-B. Park, Y.-H. Kim, B.-W. Lee, and K.-S. Rheem, "Effect of heat treatment on fatigue crack growth rate of Inconel 690 and Inconel 600," Journal of Nuclear Materials, vol. 231, no. 3, pp. 204-212, 1996.

[10] M.-K. Lim, S.-D. Oh, and Y.-Z. Lee, "Friction and wear of Inconel 690 and Inconel 600 for steam generator tube in room temperature water," Nuclear Engineering and Design, vol. 226, no. 2, pp. 97-105, 2003.

[11] W.-S. Lee, C.-Y. Liu, and T.-N. Sun, "Dynamic impact response and microstructural evolution of inconel 690 superalloy at elevated temperatures," International Journal of Impact Engineering, vol. 32, no. 1-4, pp. 210-223, 2006.

[12] W.-S. Lee and H.-C. Shen, "Comparisons of deformation and fracture behaviour of $\mathrm{PC} / \mathrm{ABS}$ blend and ABS copolymer under dynamic shear loading," Materials Science and Technology, vol. 20, no. 1, pp. 8-15, 2004.

[13] W.-S. Lee, T.-H. Chen, and Q.-J. Gong, "Dynamic shear behaviour of unweldable aluminum-scandium (Al-Sc) alloy," Materials Transactions, vol. 48, no. 3, pp. 500-509, 2007.

[14] S. S. Ezz, Y. Q. Sun, and P. B. Hirsch, "Strain rate dependence of the flow stress and work hardening of $\gamma^{\prime}$," Materials Science and Engineering A, vol. 192-193, no. 1, pp. 45-52, 1995.

[15] W.-S. Lee and Y.-C. Lin, "Strain rate and temperature dependence of dynamic shear properties of Al-Sc alloy," Materials Science and Technology, vol. 22, no. 5, pp. 571-582, 2006. 

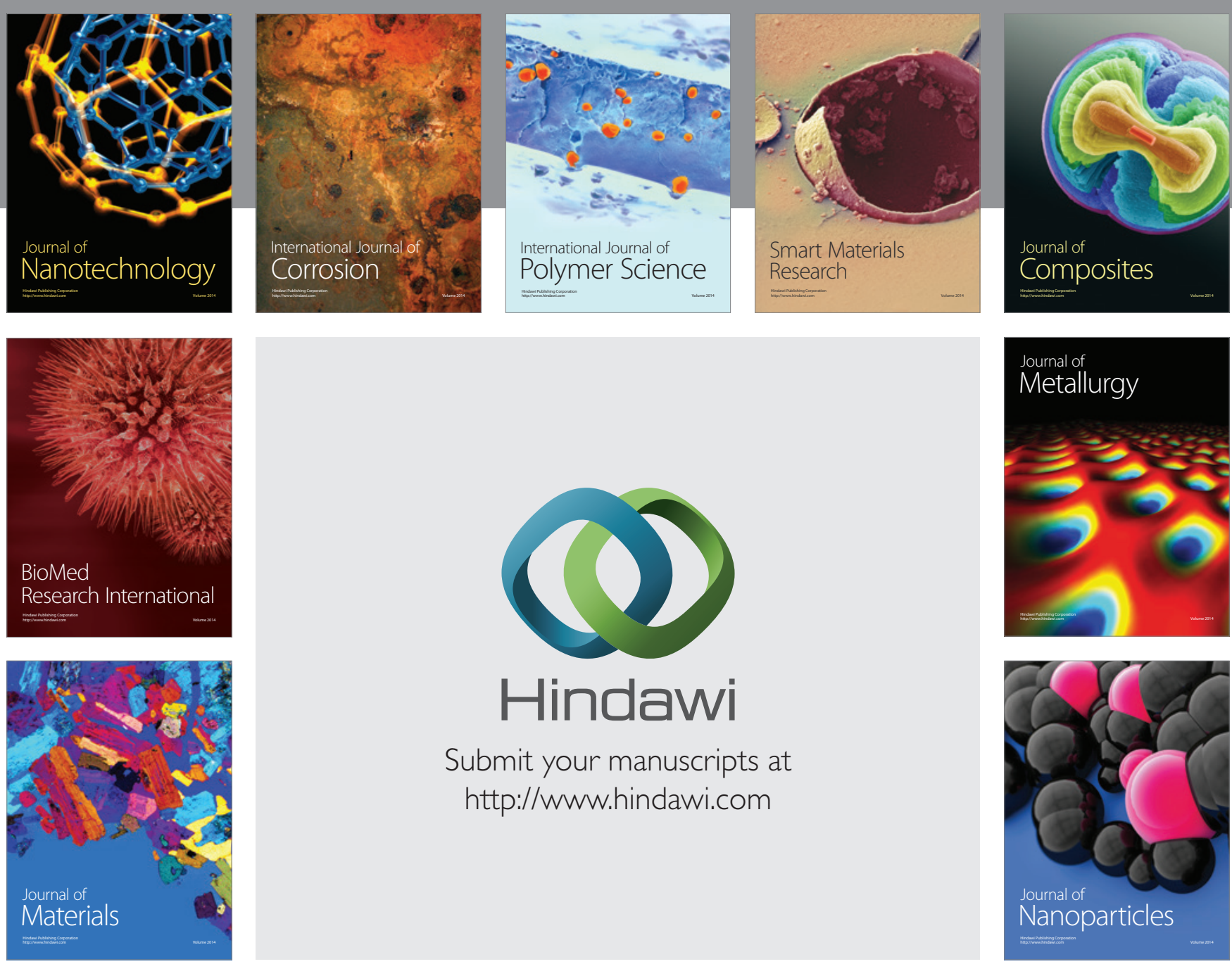

Submit your manuscripts at http://www.hindawi.com
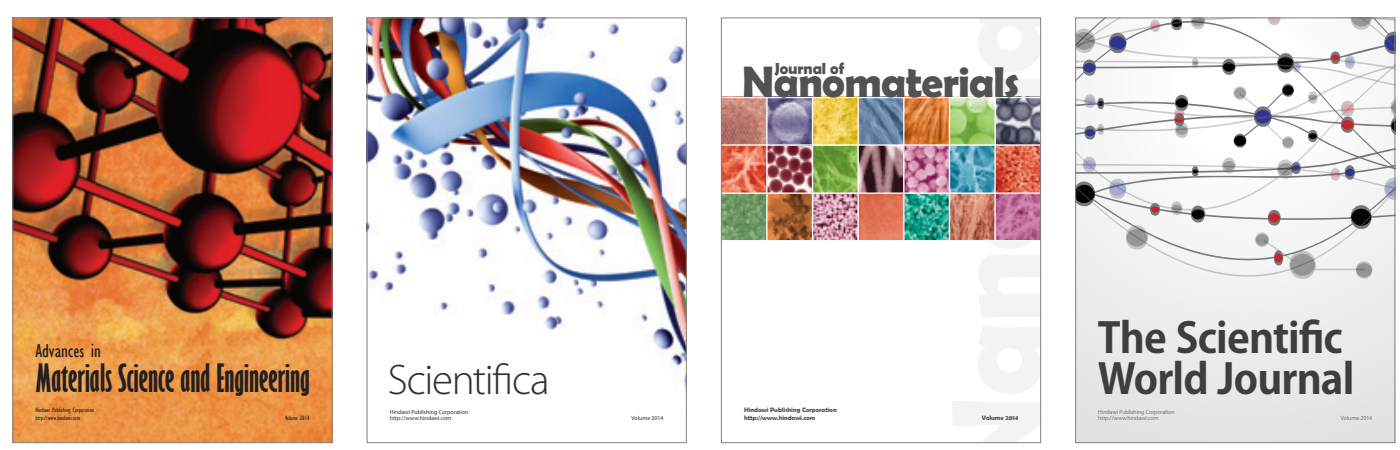

\section{The Scientific World Journal}
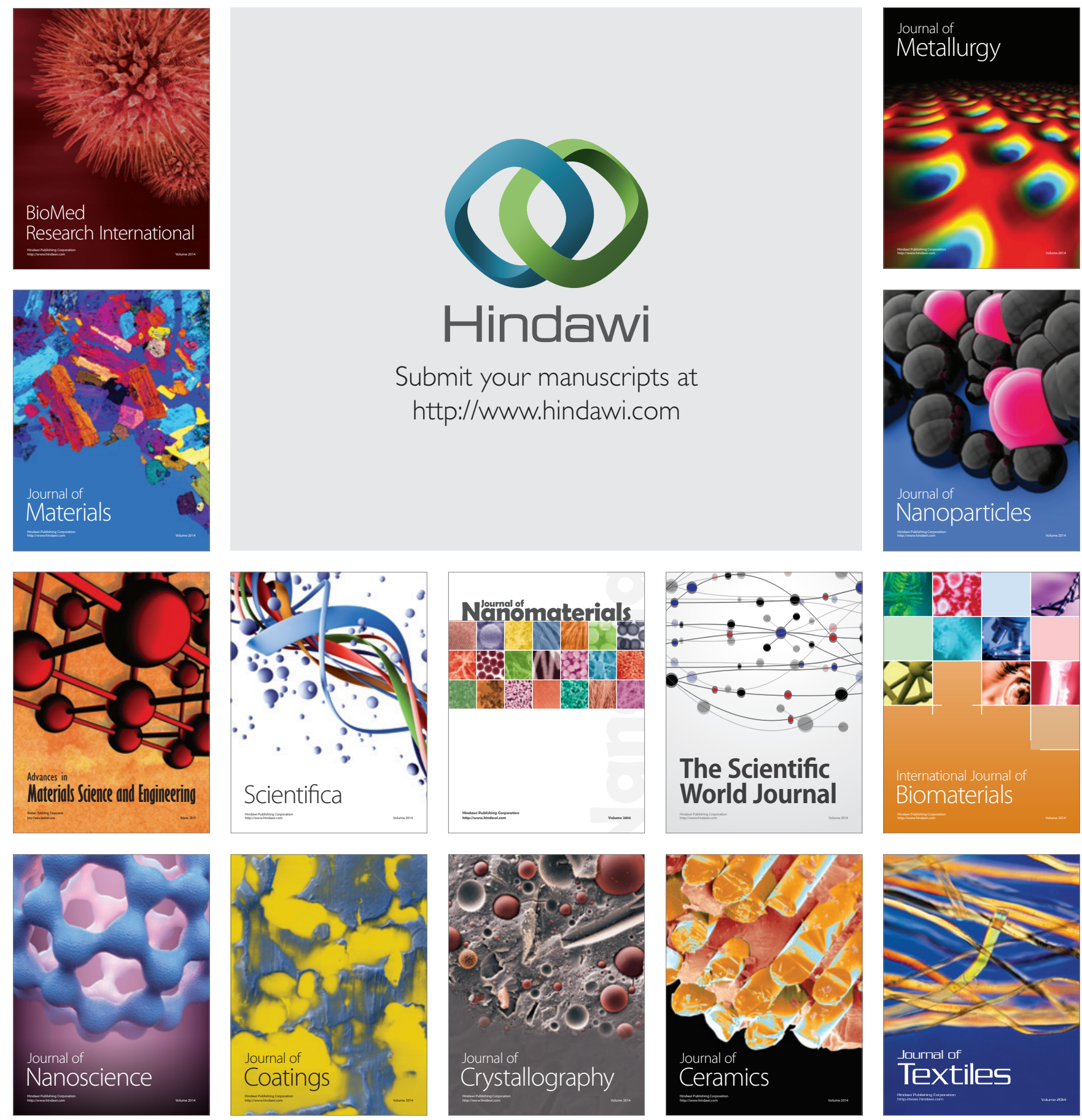